\title{
Intravital microscopy and capillaroscopically guided nail fold biopsy in scleroderma
}

\author{
Axel F G von Bierbrauer, Hans Dieter Mennel, Jan André Schmidt, Peter von Wichert
}

\begin{abstract}
Objectives-To describe the frequency, extent, and nature of microvascular lesions in patients with scleroderma by means of capillaroscopy and capillaroscopically guided nail fold biopsy, and to determine the diagnostic value of the two methods and the pathophysiological significance of the lesions described.

Methods-A cohort study was made of 24 consecutive patients with scleroderma and 10 healthy controls, using standardised clinical, serological, capillaroscopic, and histological (nail fold biopsy) techniques.

Results-All patients with scleroderma had distinct lesions of the microvascular system. Capillaroscopy revealed more than $90 \%$ of the patients to have the typical scleroderma pattern. Histologically, these changes most frequently consisted of splitting of the basal lamina, broadening of the perivascular connective tissue, perivascular round cell infiltrations, and immunoglobulin deposits (each in $60-75 \%$ of the patients) . Electron microscopy was the most sensitive method of histological examination, detecting abnormalities in $87 \cdot 5 \%$ of patients; with light microscopy and immunohistochemical techniques, abnormalities were revealed less frequently (83.3\% and $75 \%$, respectively). In contrast, normal findings were observed in most of the healthy controls: capillaroscopy $=90 \%$; histology $=80 \%$.

Conclusions-Microvascular lesions are a predominant feature in scleroderma and seem to have a central pathogenetic role in the disease. Capillaroscopy is able to identify this microangiopathy noninvasively, and capillaroscopically guided nail fold biopsy can detect the frequency and nature of the underlying ultrastructural changes. This may therefore be a useful tool in describing the pathogenetic role of the microvascular system in scleroderma.
\end{abstract}

\section{(Ann Rheum Dis 1996; 55: 305-310)}

Scleroderma or systemic sclerosis is a connective tissue disease that can affect almost all organ systems: those most frequently affected are the skin, lung, gastrointestinal tract, joints and muscles, and to a lesser extent the heart and kidneys. ${ }^{1-4}$ At present, it is classified as an autoimmune disease, ${ }^{5-8}$ but the aetiology of the condition remains unclear. Immunological processes have an important pathogenetic role that involves small vessels, particularly the vessel wall and the surrounding tissue of the capillaries. A chronic inflammatory process leads to an increasing fibrosis of these vessels and the perivascular connective tissue. ${ }^{19}$

Morphological abnormalities of nail fold capillaries have been detected in many connective tissue diseases by means of intravital capillaroscopy..$^{10-13} \mathrm{~A}$ microangiopathic pattern of high specificity and frequency has been identified in scleroderma: the so called scleroderma pattern, that shows a rather inhomogeneous, often segmental or regional distribution. Today, capillaroscopy is a standard procedure in the diagnosis of scleroderma and is regarded as one of the most useful diagnostic tools in the early stages of the disease. ${ }^{14} 15$

In order to understand the pathogenetic implications of the microvascular abnormalities seen with capillaroscopy it is important to analyse the underlying histopathological changes but, to date, histopathological data have been acquired rather unsystematically, and few studies have been performed using electron microscopy. ${ }^{16-19}$ Because of the very inconsistent involvement of the microvessels, biopsy findings in patients with scleroderma have been disappointing; in particular, the inconsistency has led to a high number of false negative results in specimens taken from macroscopically unchanged skin. Comparative studies of biopsy specimens from different regions of the body in patients with suspected scleroderma have shown the best results for biopsy specimens taken from the nail fold. ${ }^{16}$

To avoid false negative biopsy results and increase the accuracy of diagnoses based on biopsy, we have combined capillaroscopy and nail fold biopsy in a 'capillaroscopically guided nail fold biopsy' technique, taking biopsy specimens from regions with capillaroscopically identified abnormal microvessels in patients with scleroderma, and from healthy control subjects.

\section{Patients and methods}

PATIENTS

We studied 24 patients with scleroderma (two men, 22 women; mean age $46 \cdot 6$ (range 29-77) years) and 10 healthy controls subjects (one man, nine women; mean age 45.9 (range 27-72) years). The study was approved by the local ethics committee, and informed consent was obtained from all subjects. The diagnosis of scleroderma was made according to the criteria of LeRoy et $a l^{2}{ }^{2}$ and patients having diffuse scleroderma (general involvement of the skin, 


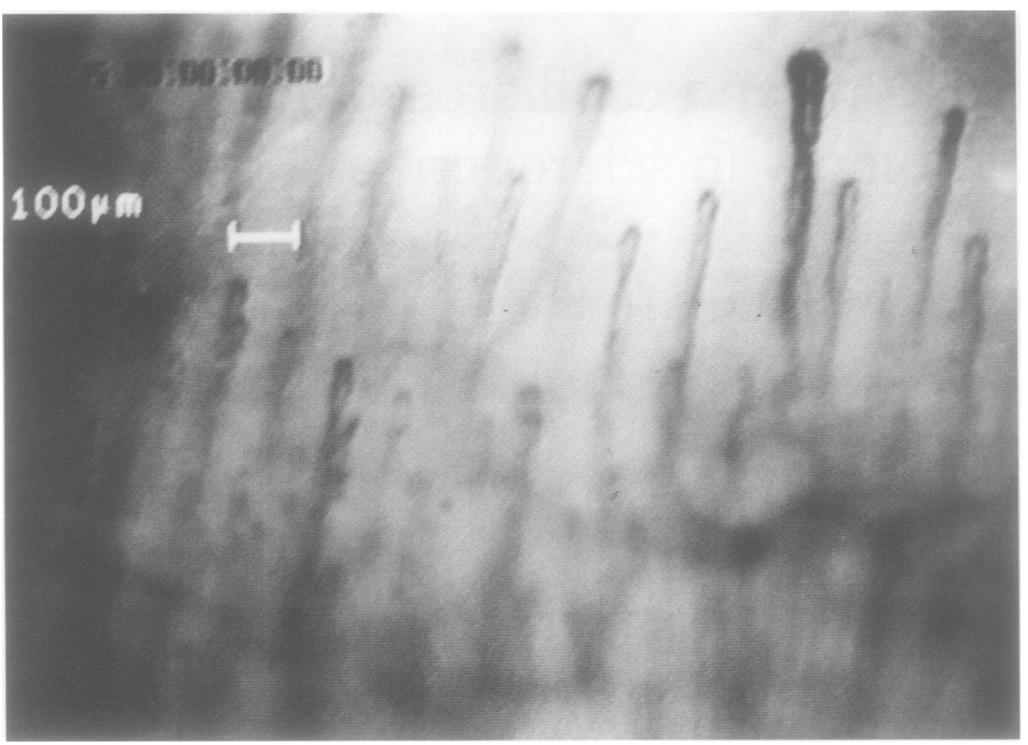

Figure 1 Nail fold capillaroscopy—regular pattern: hairpin shaped capillaries.

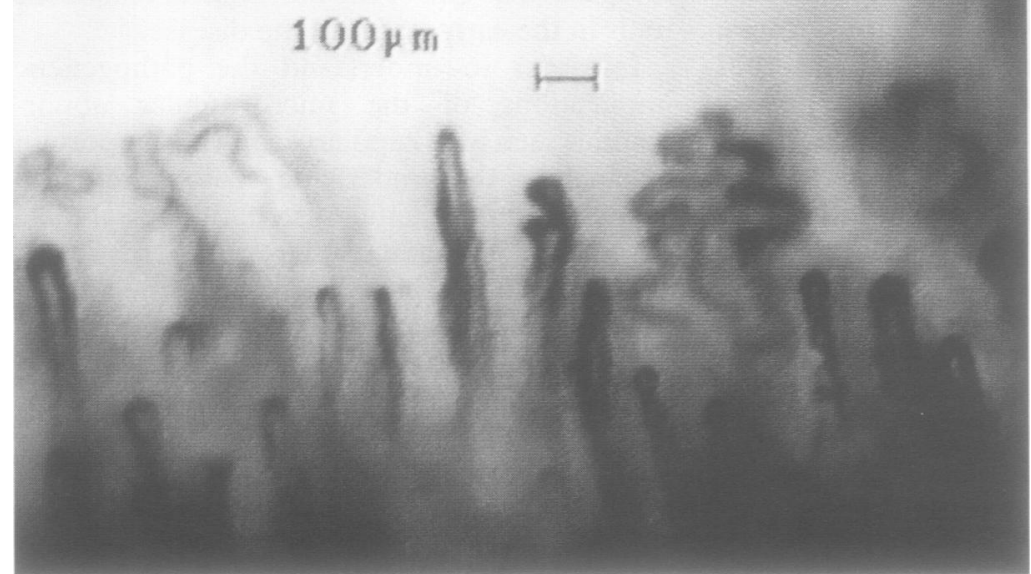

Figure 2 Nail fold capillaroscopy—minor dystrophies: bushy or coiled capillaries as a sign of inflammatory microangiopathy.

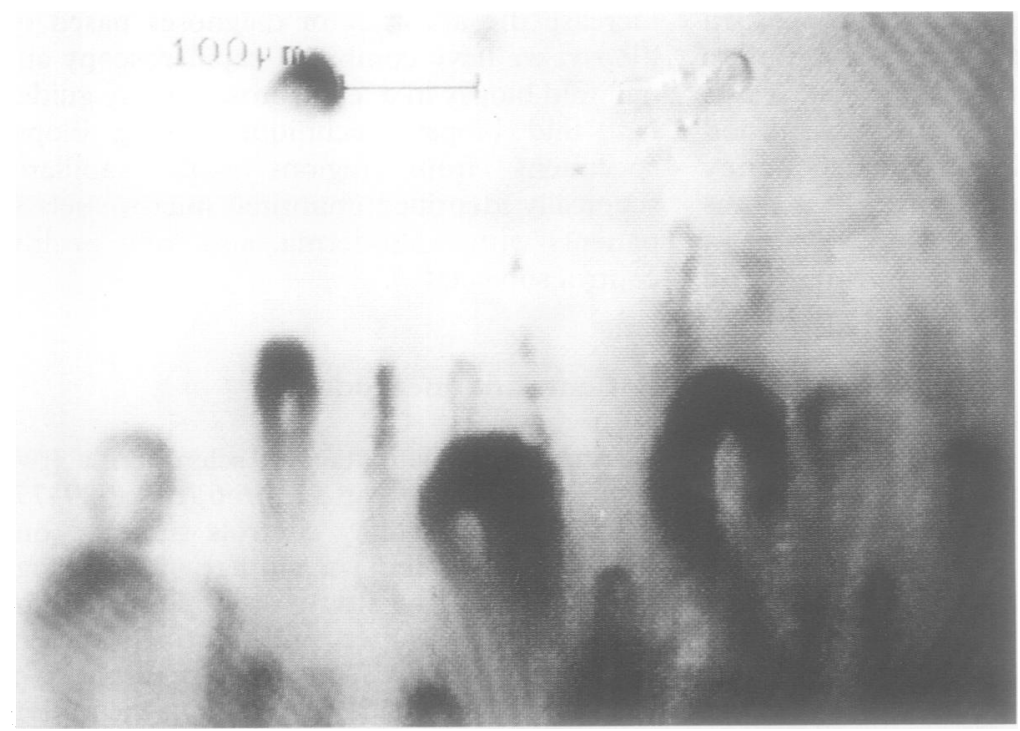

Figure 3 Nail fold capillaroscopy-scleroderma pattern: macrocapillaries, avascular fields, or both, as a sign of microangiopathy in scleroderma. intense involvement of inner organs, rapid progression) were differentiated from those having acrally limited scleroderma (acrally limited involvement of the skin, minor or no involvement of inner organs, slow progression).

Erythrocyte sedimentation rate (ESR), C reactive protein (CRP) and antinuclear antibodies (ANA)-including their fluorescent pattern and, in positive cases, their antigenic specificities (for example anticentromere, Ro(SS-A)) - were examined in the patients and healthy controls.

\section{CAPILLAROSCOPY}

Capillaroscopic examination (magnifications $\times 290$ and $\times 560$ ) was performed according to a modification of the technique described by Maricq. ${ }^{20}$ We examined the nail fold regions of all fingers of both hands (excluding the thumbs), and categorised the results into four different groups:

1) Regular pattern: hairpin shaped capillary loops; regular capillary diameters and density; no dystrophies (fig 1).

2) Functional microangiopathy: narrowing of the arterial limb of the capillary loop and dilatation of the venous limb; homogeneous capillary texture; regular capillary density.

3) Minor dystrophies: bushy, convoluted, or coiled capillaries; micro-bleedings; perivascular oedema; inhomogeneous capillary texture (fig 2). 4) Scleroderma pattern: macrocapillaries (loop width $>100 \mu \mathrm{m}$ ), avascular fields, or both; capillaries scarce $(<8 / \mathrm{mm})$ (fig 3$)$.

NAIL FOLD BIOPSY

A nail fold area containing the greatest number of morphologically abnormal capillaries was marked with a dermoscript pencil under microscopic control. Using the technique described by Schnitzler et $a l^{21}$ a local anaesthetic (1\% lignocaine, without adrenaline) was applied proximal to the marked region. The specimen (approximately $3 \times 5 \mathrm{~mm}$ ) was then obtained from the edge of the nail fold; great care was taken not to damage the nail plate during this procedure. The specimen was cut into two pieces of similar size. Finally, the region of the biopsy was compressed for a short time and, after disinfection, a dressing was applied.

\section{HISTOLOGY}

Examination of biopsy specimens was performed by light microscopy, immunohistochemistry, and electron microscopy. For light microscopy, the specimens were put into formalin, embedded in paraplast and later stained with haematoxylin and eosin. The pieces were cut in a way that allowed assessment of the epidermis, the papillary dermis, and the horizontal dermis. The immunohistochemical examinations were carried out with commercial antibodies against complement C3 and IgG, using the peroxidase-antiperoxidase method. The location and extent of deposits of IgG and complement $\mathrm{C} 3$ were examined. For electron microscopy, the specimens were set in 
Table 1 Microangiopathy in scleroderma: frequency of abnormal and normal findings in the capillaroscopic and histopatholgical examinations

\begin{tabular}{|c|c|c|c|c|}
\hline & \multicolumn{4}{|c|}{ Capillaroscopy } \\
\hline & $\begin{array}{l}\text { Scleroderma } \\
\text { pattern } \\
(\%)\end{array}$ & $\begin{array}{l}\text { Minor } \\
\text { dystrophies } \\
(\%)\end{array}$ & $\begin{array}{l}\text { Functional } \\
\text { microangiopathy } \\
(\%)\end{array}$ & $\begin{array}{l}\text { Regular } \\
\text { pattern } \\
(\%)\end{array}$ \\
\hline \multirow{4}{*}{$\begin{array}{l}\text { Scleroderma } \\
(n=24) \\
\text { Controls } \\
(n=10)\end{array}$} & $95 \cdot 8$ & $33 \cdot 3$ & $8 \cdot 3$ & - \\
\hline & - & $10 \cdot 0$ & - & $90 \cdot 0$ \\
\hline & \multicolumn{4}{|l|}{ Histology } \\
\hline & $\begin{array}{l}\text { Light } \\
\text { microscopy } \\
(\%)\end{array}$ & $\begin{array}{l}\text { Immuno- } \\
\text { histochemistry } \\
(\%)\end{array}$ & $\begin{array}{l}\text { Electron } \\
\text { microscopy } \\
(\%)\end{array}$ & $\begin{array}{l}\text { No abnormalities } \\
\text { in any method } \\
(\%)\end{array}$ \\
\hline \multirow{2}{*}{$\begin{array}{l}\text { Scleroderma } \\
(n=24) \\
\text { Controls } \\
(n=10)\end{array}$} & $83 \cdot 3$ & 75.0 & $87 \cdot 5$ & $4 \cdot 2$ \\
\hline & $10 \cdot 0$ & $10 \cdot 0$ & $10 \cdot 0$ & $80 \cdot 0$ \\
\hline
\end{tabular}

Table 2 Frequency and nature of the main histopathological features in scleroderma $(n=24)$

\begin{tabular}{lll}
\hline Technique & Feature & $\begin{array}{l}\text { Frequency } \\
\text { (\%) }\end{array}$ \\
\hline Light microscopy: & Broadening/increased amount of connective tissue & $75 \cdot 0$ \\
& Perivascular round cell infiltrations & $70 \cdot 8$ \\
& Perivascular oedema & 37.5 \\
Immunohistology: & Enhanced perivascular and vessel wall deposits of C3 & $66 \cdot 7$ \\
& Enhanced perivascular and vessel wall deposits of IgG & $62 \cdot 5$ \\
Electron microscopy: & Broadening and splitting of basal lamina & $66 \cdot 7$ \\
& Broadening/increased amount of connective tissue & 62.5 \\
& Fibroblasts and mast cells & $45 \cdot 8$ \\
& Perivascular oedema & $41 \cdot 7$ \\
& Perivascular deposits of amorphic material & 25 \\
& Narrowing of capillary lumina & 16.7 \\
\hline
\end{tabular}

glutaraldehyde, embedded in Epon, and later polymerised. The epidermis was cut in such a way that the dermal papilla could be assessed in cross section. The correct orientation was checked by a semimicrosection. The specimens were identified using a Zeiss EM 109 and photographed.

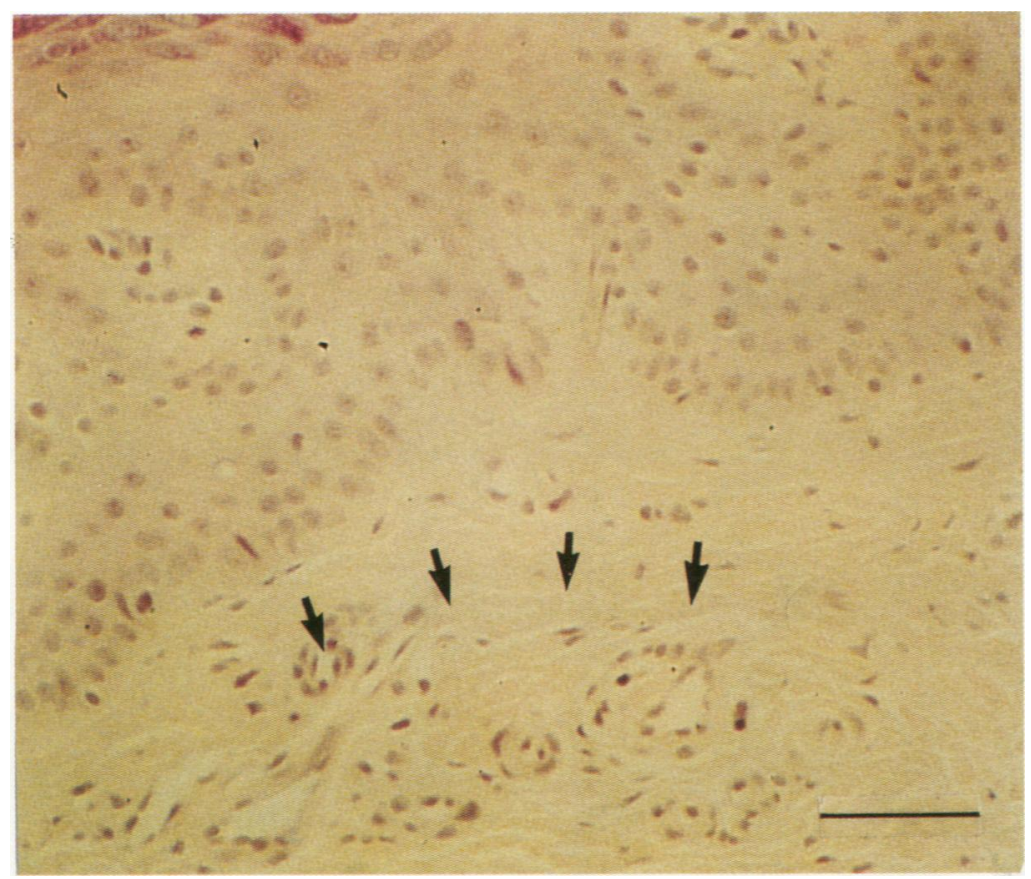

Figure 4 Nail fold biopsy-light microscopy: infiltration of inflammatory cells along a vascular conglomerate (arrows) in the dermal horizontal stratum. Haematoxylin and eosin. Horizontal bar represents $50 \mu \mathrm{m}$.

\section{Results}

There were no serious complications relating to the biopsy procedure itself or wound healing. As the procedure of granulation can start from three sides, wound healing is very fast: after a few months the biopsy region is virtually unidentifiable.

CLINICAL FINDINGS AND LABORATORY TESTS

Eight patients had diffuse scleroderma with substantial involvement of lung, heart, and kidney. Sixteen patients showed the acrally limited form. The diagnosis was made at the time of our examination in all but five patients. The patient with the longest duration of disease had had scleroderma for seven years. All patients showed involvement of the skin to a variable extent, and all but three had Raynaud's syndrome.

Laboratory tests revealed $66 \cdot 7 \%$ of the patients to have an increased ESR, while only $37.5 \%$ had increased CRP. Positive ANA were found in $91.7 \%$ of patients, and in $79.2 \%$ the ANA titre was greater than 100 .

History, clinical, and laboratory examinations of the healthy controls revealed signs of neither a macro or microangiopathy, nor a rheumatic disease.

\section{CAPILLAROSCOPY}

Table 1 summarises the findings. All but three patients $(87.5 \%)$ had a typical scleroderma pattern. In two patients it was not possible to differentiate unequivocally between a scleroderma pattern and functional microangiopathy. In one patient we found no scleroderma pattern, but minor dystrophies. In addition to the scleroderma pattern, seven patients showed distinct signs of minor dystrophies. We failed to demonstrate normal capillaroscopy in any patient with scleroderma.

Nine of the 10 healthy controls had no abnormalities of capillaroscopy. One subject had a single bushy capillary (minor dystrophy) on three of eight fingers examined (table 1).

\section{HISTOLOGY}

Tables 1 and 2 summarise the findings. In light microscopy, $83.3 \%$ of the patients exhibited pathological features, most frequently perivascular round cell infiltrations and increased amounts of connective tissue (fig 4). In electron microscopy, signs of microangiopathy were found in 21 patients $(87.5 \%)$. The main features were broadening and splitting of the basal lamina, an increased amount of connective tissue, perivascular oedema, and increased numbers of mast cells and fibroblasts (fig 5). Immunohistochemically, $75 \%$ of the patients showed increased deposits of complement C3, IgG, or both, in the vessel wall and in the perivascular region (fig 6). Signs of microangiopathy were consistently observed by all three methods of histological examination in $70.8 \%$ of the patients. In two patients, abnormalities were evident in only one of the histological examinations. One patient had completely 


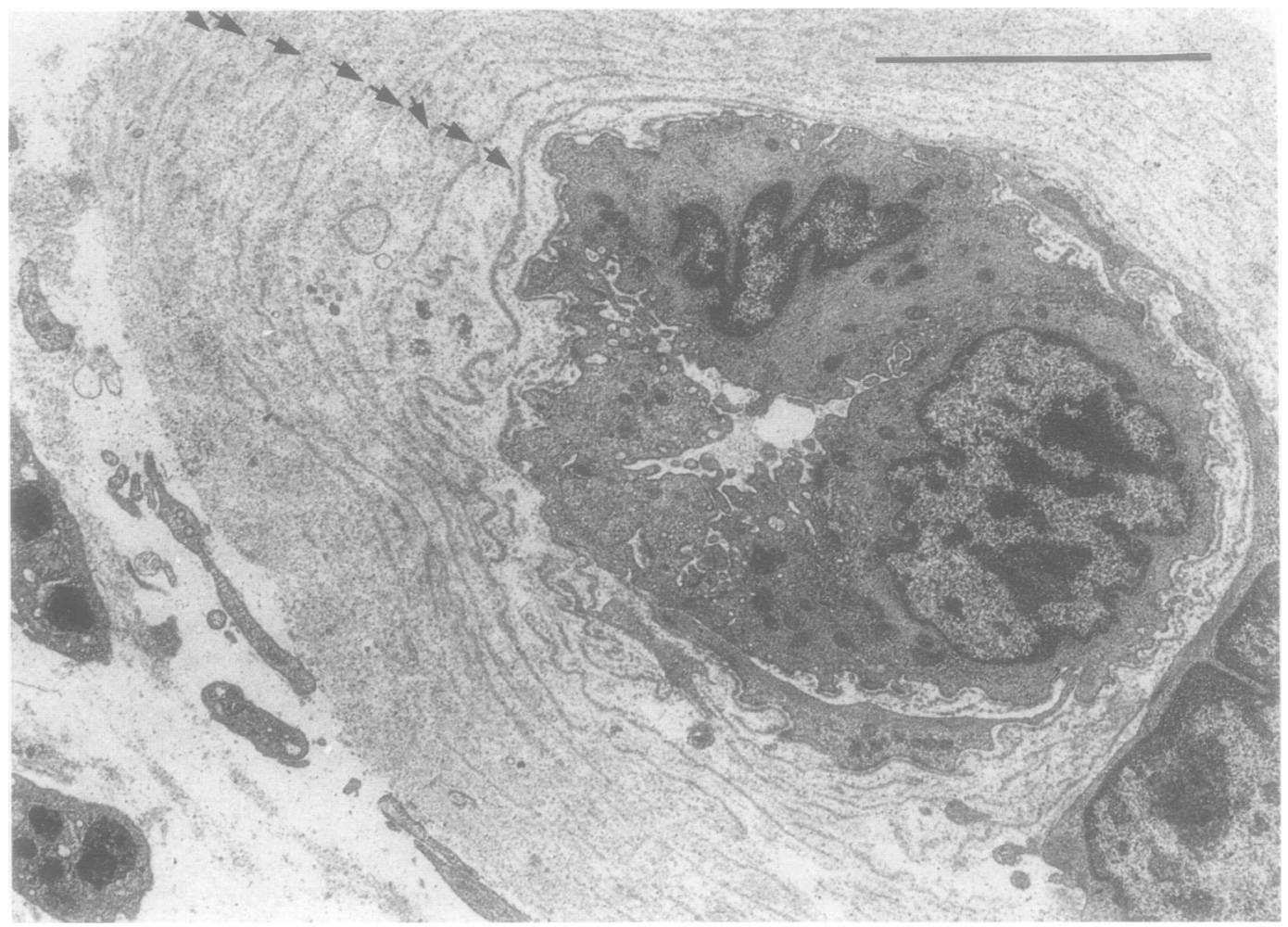

Figure 5 Nail fold biopsy-electron microscopy: broadening and splitting into multiple layers (arrows) of the basal lamina. Horizontal bar represents $1 \mu \mathrm{m}$.

normal results from all the histological tests; this was the patient in whom nail fold microscopy did not reveal a scleroderma pattern.

In eight of the 10 healthy control subjects, we found no abnormalities with all three methods of histological examination. In one healthy person, round cell infiltrations were observed by light microscopy. Another showed moderate histopathological abnormalities in immunohistochemistry and electron microscopy: this was the person showing minor dystrophies in capillaroscopy. One year later this subject presented with an increased ESR and arthralgia. To date it has not been possible to make an unequivocal classification of his collagen tissue or rheumatic disease.

\section{Discussion}

In scleroderma, identification of the microangiopathy is very important, both for making the diagnosis and, especially, for making that

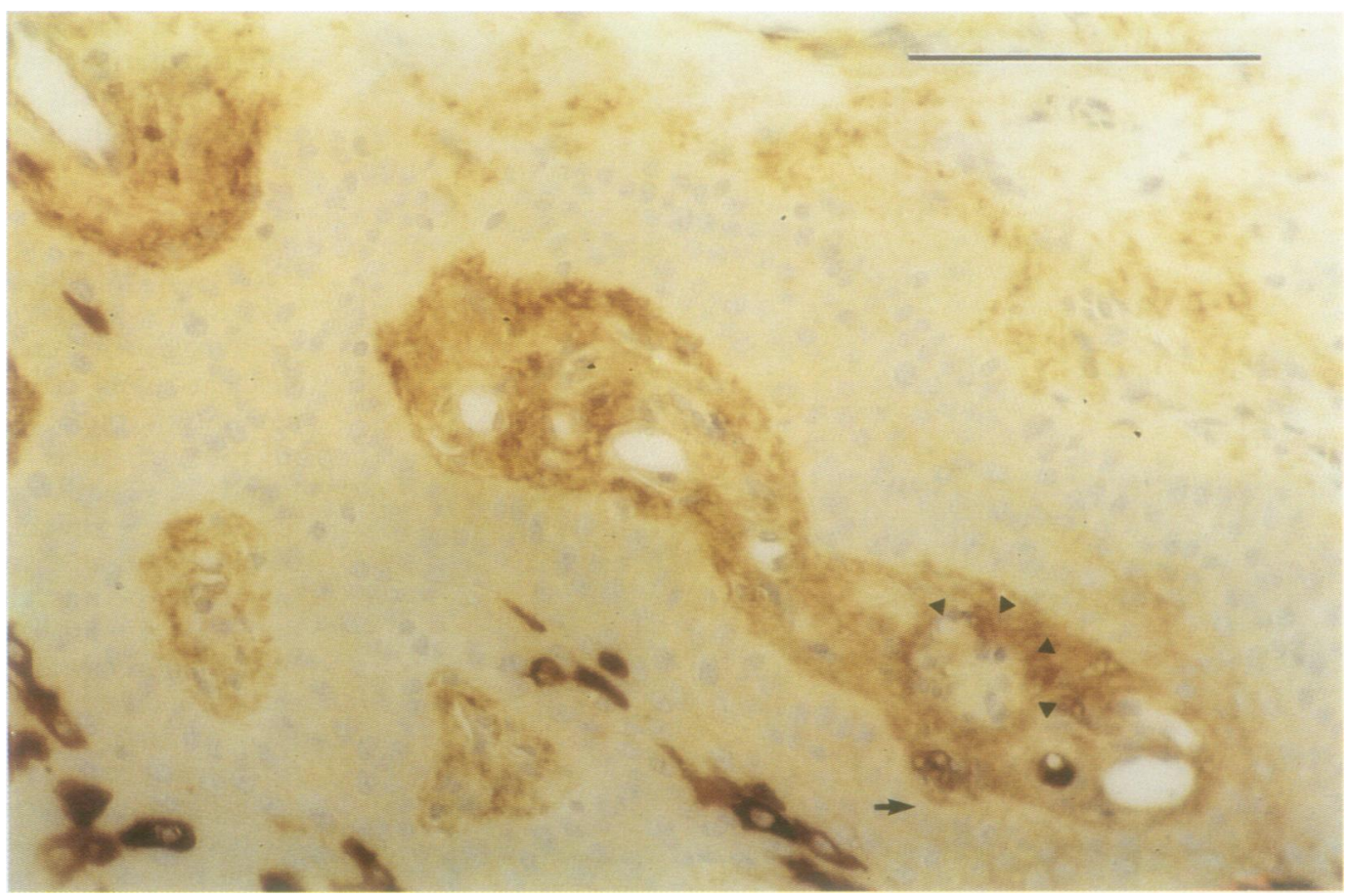

Figure 6 Nail fold biopsy-immunohistochemistry: immunoglobulin deposits, both perivascular (arrowheads) and in single cells (arrow). IgG-peroxidase-antiperoxidase. Horizontal bar represents $50 \mu \mathrm{m}$. 
diagnosis early. ${ }^{1}{ }^{1422-24}$ In this study, we were able to show that, as examined by intravital capillaroscopy, more than $90 \%$ of patients with scleroderma had morphological abnormalities of the nail fold capillaries (scleroderma pattern). Furthermore, in biopsy specimens from regions containing morphologically abnormal capillaries, histopathological changes in capillaries and perivascular areas were also found in more than $90 \%$ of the patients. The most striking histopathological features were broadening and splitting of the basal lamina (electron microscopy), increased deposits of complement $\mathrm{C} 3$ and IgG in the vessel wall and the perivascular area (immunohistochemistry), and perivascular round cell infiltrations and oedema formation (light microscopy).

In contrast, none of the healthy controls showed a scleroderma pattern or histopathological abnormalities of the vessels consistently by all three of the histological methods. The particular case of a healthy control in whom we found abnormalities in capillaroscopy and histology, and who later developed a connective tissue disease, demonstrates that capillaroscopic and histological examination may serve as useful tools in the early diagnosis of vasculitis. These results agree with prospective studies that found capillaroscopic abnormalities occurring some years before clinical symptoms of a collagen tissue disease had developed (though no histological data were given). ${ }^{13}$

Our results underline the outstanding diagnostic value of capillaroscopic examination in scleroderma. Regarding the frequency of capillary abnormalities, our findings agree with those of former studies. ${ }^{12}{ }^{13}$ The histopathological results confirm the importance of the capillaroscopically demonstrated scleroderma pattern described by Maricq. ${ }^{12}$ Recognition of the development of this scleroderma pattern is always based on ultrastructural (histopathologically confirmed) changes, which could be identified in our study as (immunologically) induced changes in the vessel wall and the perivascular tissue.

There are few data available concerning histological abnormalities of capillaries in collagen vascular diseases. Among the relevant studies, some of the histopathological abnormalities that we observed have been described: changes of the basal lamina, ${ }^{19}{ }^{25}$ enhanced deposits of immunoglobulins in the vessel wall, ${ }^{16} 2627$ and perivascular round cell infiltrations. $^{22} 28$ The disappointing histopathological results formerly obtained for connective tissue diseases may be attributable to the site from which the biopsy specimen was taken. In the present study, by taking specimens from regions containing morphologically abnormal capillaries, we increased the diagnostic accuracy and decreased the number of false negative biopsy results, compared with former studies. ${ }^{19}$ 26-28 Comparative studies of different sites of biopsy in the same individual have shown the superiority of nail fold biopsy, particularly with respect to abnormalities of the basal lamina and immunoglobulin deposits. ${ }^{16}$ Because we performed capillaroscopically guided nail fold biopsy, we found considerably more histopathological abnormalities than had been observed in studies in which biopsy specimens were taken blindly, ${ }^{25} 29$ and consequently were able to define in precise detail the frequency, nature, and diagnostic value of the histological changes.

The histopathological changes seen in scleroderma are not strictly specific for the microangiopathy, however. Similar histopathological changes have also been found in lupus erythematosus, mixed connective tissue disease, dermatomyositis, and diabetes..$^{30-33}$ There seems to be a partially uniform reaction of the tissue to what are probably different pathogenetic mechanisms.

The processes of cellular infiltration and immunoglobulin deposition in the vessel wall lead to a leakage of the endothelial barrier. By demonstrating the splitting of the basal lamina, we were able to disclose the morphological (ultrastructural) correlate of the increased capillary permeability, which we observed capillaroscopically (perivascular oedema, microbleedings). The increased sodium fluorescein extravasation in patients with scleroderma ${ }^{34}$ and diabetes $^{35}$ also has its histomorphological basis in these ultrastructural changes of the basal lamina.

In conclusion, our study has demonstrated the nature and frequency of capillaroscopic and histopathological changes in scleroderma. Because it makes possible the identification of microangiopathy, the technique of capillaroscopy (more so than histology) is of major diagnostic importance even in the early stage of this disease. Histology is able to reveal the underlying ultrastructural changes in detail. Round cell infiltrations, broadening of the connective tissue layer, oedema formation, splitting and broadening of the basal lamina, and deposits of complement $\mathrm{C} 3$ and $\mathrm{IgG}$ are frequently visible, and suggest an immunological nature of the microangiopathy, which obviously has an essential role in the pathogenesis of scleroderma.

1 Krieg T, Meurer M. Systemic scleroderma-clinical and pathophysiologic aspects. $\mathcal{f} \mathrm{Am}$ Acad Dermatol 1988; 18: 457-84.

2 LeRoy E C, Black C, Fleishmayer R, et al. Scleroderma (systemic sclerosis). Classification, subsets and pathogenesis. F Rheumatol 1988; 15: 202-5.

3 Subcommittee for Scleroderma Criteria of the American Rheumatic Association Diagnostic and Therapeutic Criteria Committee. Preliminary criteria for the classification of systemic sclerosis (scleroderma). Arthritis Rheum 1980; 23: 581-90.

4 Winkelmann $R$ K. Classification and pathogenesis of scleroderma. Mayo Clin Proc 1971; 46: 83-91.

5 Genth E, Mierau R, Genetzky P, et al. Immunogenetic associations of scleroderma-related antinuclear antiassociations of scleroderma-related anting

6 Jablonska S, Chorzelski T P, Blaszczyk M, Glinski W. Immunologic phenomena in scleroderma. In: Beutner $\mathrm{E}$, Chorzelski T P, Bean S F, eds. Immunopathology of the skin, 2nd edn. New York: Wiley, 1979; 363-80.

7 Kallenberg C G M, DeJong N C J M, Walstra T M, Kardaun $S$, Hauwthe $T$. In vivo antinuclear antibodies (ANA) in biopsies of normal skin: diagnostic significance and relation to serum ANA. $\mathcal{f}$ Rheumatol 1983; 10: 733-40.

8 Rodnan G P. Progressive systemic sclerosis (scleroderma) In: Parker C, ed. Clinical immunology. Philadelphia: W B Saunders, 1980; 784-814.

9 Jablonska S, Chorzelski T, Blaszczyk M. Relation between scleroderma and collagen diseases. In: Jablonska S, ed Scleroderma and pseudoscleroderma, 2nd
Polish Medical Publishers, 1975; 35-51.

10 Houtman P M, Kallenberg C G M, Wouda A A, The T H. Decreased nailfold capillary density in Raynaud's 
phenomenon: a reflection of immunologically mediated local and systemic vascular disease? Ann Rheum Dis 1985 ; 44: 603-9.

11 Maricq $H R$. The microcirculation in scleroderma and allied diseases. In: Davis E, ed. Advances in microcirculation. Raynaud's features, acrocyanosis and cryoimmunoproteins, Vol 10. Basel: Karger, 1982; 7-52.

12 Maricq H R, LeRoy E C, D'Angelo W, et al. Diagnostic potential of in vivo capillary microscopy in scleroderma and related disorders. Arthritis Rheum 1980; 23: 183-9.

13 Maricq H R, Weinberger A B, LeRoy E C. Early detection of scleroderma-spectrum disorders by in vivo capillary microscopy. A prospective study of patients with Raynaud's phenomenon. F Rheumatol 1982; 9: 289-91.

14 Krieg T, Braun-Falco O, Meurer M, Hein R, von GizyckiNienhaus B. Die systemische Sklerodermie. Dtsch Arzteblatt 1992; 35: 147-51.

15 Maricq $H \quad R$. Nailfold capillary photography. In: Messmer $\mathrm{K}$. Hammersen $\mathrm{F}$, eds. Progress in applied Messmer K, Hammersen F, eds. Progress in applied
microcirculation. Techniques in clinical capillary microscopy,

16 Chen Z Y, Dobson R L, Ainsworth S K, Silver R M Rust R M, Maricq H R. Immunofluorescence in skin specimens from three different biopsy sites in patients with scleroderma. Clin Exp Rheum 1985; 3: 11-6.

17 Maricq H R. Nailfold biopsy in scleroderma and related disorders. Dermatologica 1984; 168: 73-7.

18 Schnitzler L, Baran R, Verret J L. La biopsie du repli susungueal dans les maladies dites du collagene. $A n n$ Dermatol Venereol (Paris) 1980; 107: 777-85.

19 Thompson R P, Harper F E, Maize J C, Ainsworth S K, LeRoy E C, Maricq H R. Nailfold biopsy in scleroderm and related disorders. Arthitis Rheum 1984; 27: 97-103.

20 Maricq H R. Widefield capillary microscopy. Technique and rating scale for abnormalities seen in scleroderma and related disorders. Arthritis Rheum 1981; 24: 1159-65.

21 Schnitzler L, Baran R, Civatte J, Schubert B, Verret J L, Hurez D. Biopsy of the proximal nail fold in collagen diseases. F Dermatol Surg 1976; 2: 313-5.

22 Fiessinger JN, Camilleri JP, Mignot J. La microangiopathie sclerodermique. Hypotheses physiopathogeniques. Rev Med Intern 1980; 1: 61-4.
23 Norton W L, Hurd E R, Lewis D C. Evidence of microvascular injury in scleroderma and systemic lupus erythevatosus: quantitative study of the microvascular bed. $\mathcal{f}$ Lab Clin Med 1968; 71: 919-33.

24 Norton $W \mathrm{~L}$, Nardo J M. Vascular disease in progressive systemic sclerosis (scleroderma). Ann Intern Med 1970; 73: 317-24.

25 Michalowski R, Kudejko J. Electron microscopic observations on skeletal muscle in diffuse scleroderma. $\mathrm{Br} \mathcal{F}$ Dermatol 1966; 8: 24-8.

26 Chen Z Y, Ainsworth S K, Maricg H R, Silver R M, Dobson $\mathrm{R} \mathrm{L}$. Immunofluorescence in scleroderma [Abstract]. Clin Res 1983; 31: 612A.

27 Connolly S M, Winkelmann $R \quad K$. Direct immunofluorescent findings in scleroderma syndromes. Acta Derm Venerol (Stockh) 1981; 61: 29-36.

28 Fisher E R, Rodnan G P. Pathologic observations concerning the cutaneous lesion of progressive systemic sclerosis: ing the cutaneous lesion of progressive systemic sclerosis: an electron microscopic, histochemical and immuno-

29 Leinwand I, Duryee A W, Richter M R. Scleroderma (based on a study of over 150 cases). Ann Int Med 1954; 41: $1003-41$.

30 Friederici H H R, Tucker W R, Schwartz T B. Observations on small blood vessels of skin in the normal and in diabetic patients. Diabetes 1966; 15: 233-50.

31 von Bierbrauer A, Mennel H D, von Wichert P. Kapillarmikroskopie und Nagelfalzbiopsie bei Mikroangiopathien. Klin Wochenschr 1992; 69: 387-8.

32 Siperstein M D, Unger R N, Madison L L. Studies of muscle capillary basement membranes in normal subjects, diabetic and prediabetic patients. F Clin Invest 1968; 47: 1973-99.

33 Fleischmajer R, Perlish J S, Reeves J R T. Cellular infiltrates in scleroderma skin. Arthritis Rheum 1977; 20: 975-84.

34 Bollinger A, Jäger K, Siegenthaler W. Microangiopathy of systemic sclerosis: evaluation by dynamic fluorescence videomicroscopy. Arch Intern Med 1986; 146: 1541-5.

35 Bollinger A, Frey J, Jäger K, Furrer J, Seglias J, Siegenthaler W. Patterns of diffusion through skin capillaries in patients with long-term diabetes. New Engl f Med 1982; 18: 1305-10. 